\title{
La investigación un nexo entre el desarrollo tecnológico científico y la pobreza en América Latina
}

J Selva Andina Biosph. 2018; 6(2):26-27.

No cabe duda que la investigación juega un rol fundamental en el desarrollo tanto económico y social a nivel global. Sin embargo, parece que este punto de vista no es compartido por algunas entidades en América Latina. Actualmente la inversión estatal en investigación e innovación (I+I) es liderada por Corea del Sur, seguida por Japón, Alemania y Estados Unidos, países que invierten el 4.23\%, 3.29\%, $2.93 \%$ y $2.79 \%$ de su producto bruto interno respectivamente (PBI) ${ }^{1}$. Pero no solo el Estado invierte en I+I, sino también lo hacen las empresas privadas, otorgándoles a los investigadores, o centros de investigación, gran cantidad de recursos para desarrollar investigaciones de gran impacto que permitan encaminar nuevas estrategias y/o tecnologías, y por tanto que estas generen riqueza en sus países.

¿Pero que viene sucediendo en esta parte del mundo?, ciertamente la clase política de los países ubicados en esta latitud del globo aún no han generado la cultura de inversión en I+I, al contrario, los recursos destinados a $\mathrm{I}+\mathrm{I}$ siempre fueron vistos como un gasto sin retorno y no como una inversión estratégica. Solo Brasil se destaca en términos de inversión en I+I con el $1.21 \%$ de su PBI, que comparado con países europeos, este gigante sudamericano, aún tiene mucho camino por recorrer. ¿Y qué de la situación de los otros países sudamericanos??, en estos el panorama no es muy alentador, por ejemplo, Perú solo invierte el $0.15 \%$ de su PBI, mientras que Ecuador el $0.22 \%$, en el caso de Chile y Argentina, la inversión destinada a I+I es de 0.42 y $0.65 \%$, respectivamente ${ }^{2}$.

Un producto de la investigación son las patentes ${ }^{3}$, éstas pueden ser en esencia un indicador de la situación actual del I+I de cada país. De ahí que los países de América del Sur se ven en amplia desventaja frente a sus pares, por señalar, para el año 2017 el Perú otorgó 638 patentes, mientras que Japón obtuvo 21712 patentes para ese mismo año. Estos datos reafirman el poco interés que tienen nuestros gobernantes en la I+I.

No parece una casualidad que países que más invierten en I+I sean también aquellos con mejores condiciones de vida o con mayores oportunidades de desarrollo, y por ende menos pobreza. La relación 
inversa entre la mayor inversión en I+I con menores niveles de pobreza, debería hacer entender tanto al sector estatal como al privado, la importancia del I+I para salir del subdesarrollo. Una vez entendido que la I+I no es un gasto, sino una inversión a mediano y largo plazo, se deben destinar mayores recursos en I+I, y como consecuencia de ellos mejorar los niveles de vida de nuestras sociedades.

\section{Literatura citada}

1. Dinero [Internet]. Los países que más invierten en investigación e innovación. 2018 [citado 25 de noviembre de 2018]. Recuperado a partir de: https://www.dinero.com/edicion-impresa/mundo/articulo /paises-que-invierten-en-innovacion/254269.

2. Índex Mundi[Internet].Gasto en investigación y desarrollo (\% del PIB). 2018 [citado 25 de noviembre de 2018]. Recuperado a partir de: https://www.indexmundi.com/es/datos/indicadores/GB.XPD.RSDV. GD.ZS

3. Instituto Nacional de Defensa de la Competencia y de la Protección de la Propiedad Intelectual. Las patentes y su importancia en investigación cientifica. 2018 [citado 25 de noviembre de 2018]. Recuperado a partir de: https://www.indecopi.gob.pe/documents/20791/203175/LAS+PATENTES + Y+SU+IMPORTANCIA+EN+LA+INVESTIGACI\%E2\%80\%A1N+CIENTIFICA.pdf/9b789a1d3537-3ebc-4e2d-4a94ddf4a72c

Borjas-Ventura Ricardo Facultad de Agronomía Departamento de Fitotecnia 